\title{
La idea de Nación en Ricardo Palma
}

Por Carlos Alberto Pérez Garay 
Licenciado en Historia por la Universidad Nacional Mayor de San Marcos. Se desempeña como docente en la Universidad Ricardo Palma. Es especialista en temas de historia política, intelectual y literaria. 
El presente trabajo es una aproximación al estudio de las ideas del escritor peruano, Ricardo Palma Soriano, en torno at tema de la nación peruana entre los siglos XIX y XX, a partir de su biografia y trabajo potitico, asi como su obra literaria que abarca casi todos los géneros.

Palabras clave: identidad, romenticismo, Bohemia Limeña, idioma, racismo, Nación.

\section{Introducción}

Para entender la idea de nación en Ricardo Palma - trabajo nada sencillo, por cierto-, trataremos de centrarnos en la trayectoria vital del ilustre escritor, desde su etapa de juventud a su etapa de madurez, y en su obra literaria. Precisamente, el estudio de las distintas etapas de la vida del escritor peruano y el análisis de su obra nos permitirá conocer y comprender la evolución de sus ideas sobre el concepto de nación. Varias de sus ideas sobre este concepto se pueden vislumbrar a través de su discurso político e ideológico, las cuales fueron elaboradas en las diversas actividades en la que se desempeñó: escritor, político, periodista, editor, bibliotecario, etc.

Asimismo, trataremos de señalar la importancia que tienen, hasta el día de hoy, las Tradiciones Peruanas, como base fundamental 
para la construcción de nuestro imaginario nacional (tarea que por lo general ha sido vista con mayor intensidad por la crítica literaria), la valoración de una historia en común, que implique a todos los peruanos, el rescate de la memoria colectiva y el surgimiento y desarrollo de la identidad nacional.

Muchos estudiosos de la obra de Palma no han logrado ocuparse del tema que estamos presentando, debido a su poca relevancia y porque se ha encasillado mucho a Palma como un escritor pasatista, desentendido de los problemas sociales de su época y la realidad del país, lo cual es totalmente falso. Si bien no fue un reconocido ensayista de la talla de González Prada, el tradicionista se dio tiempo para escribir algunos ensayos sobre temas políticos, sociales, educativos, culturales y literarios de su tiempo. Precisamente, en estos ensayos, a los que podemos añadir también sus reiterados juicios de valor expuestos en sus cartas, así como sus comentarios expresados en sus tradiciones, podemos ofrecer una idea aproximada sobre como concebía Palma a la nación peruana, sea esta a través de algunos de sus elementos o también por todo el conjunto.

Esperemos que este trabajo pueda servir —más adelantepara un ambicioso proyecto que sirva de contribución para el conocimiento de las ideas del escritor de las Tradiciones, y que nos permita comprender uno de los discursos más originales que tuvo uno de nuestros principales intelectuales en torno a la nación peruana.

\section{Ricardo Palma. Orígenes. La relación con la nación}

Figura egregia de nuestra literatura nacional, Ricardo Palma Soriano nació en Lima el 7 de febrero de 1833 . Fue hijo de un modesto comerciante informal y de una mujer de raíces negras. Siendo apenas un niño, sus primerias correrías infantiles las 
realizó en una ciudad plagada todavía de costumbres coloniales. En efecto, era muy frecuente, por ese tiempo, escuchar la voz de los pregoneros, las campanas de las iglesias y presenciar a algunas mujeres inconfundiblemente vestidas con la tradicional saya y el manto. Habituado a esa Lima de raigambre colonial, el futuro escritor logró conocer y relacionarse con muchos personajes de diversa extracción social y procedencia étnica. Blancos, mestizos, indios, pardos, esclavos, libertos, formaron parte de ese paisaje social urbano. Sin embargo, la fuerte división y antagonismo social de estos grupos y el poco interés de parte del Estado hacia difícil la posibilidad de construir la nación peruana.

Como muchos escolares, Palma inicialmente debió de identificarse con los rasgos étnicos, culturales y procedencia de sus padres. En sus clases, sobre todo en las de historia, debió de conocer el significado de la patria, el culto a los héroes y el amor a la tierra que lo vio nacer. El concepto de nación, en términos políticos (ético y moral, basado en una suma de voluntades), no estaba muy difundido. No obstante, es posible que haya conocido el significado de este concepto, pero en los términos culturales (raza, lengua).

Precisamente durante su etapa escolar, su origen racial lo llevó a ser objeto de burla de sus compañeros. Blanquearse, ascender socialmente, era uno de los objetivos que se trazó para dejar de ser víctima de tan marcada exclusión social. En tal sentido, la educación constituyó el principal vehículo de ascenso social. Con la ayuda de su padre y el mecenazgo estatal, obtuvo una beca para cursar, en 1849, estudios en el Convictorio de San Carlos, el más importante centro de instrucción superior de Lima. Al iniciar sus estudios en ese plantel, Palma logró relacionarse con diversos estudiantes de distinta extracción social. Algunos eran hijos de distinguidas familias criollas y provincianas, como por ejemplo los hermanos Manuel, Luciano y Luis Benjamín Cisneros (Huánuco) y otros de su misma condición. 
Como estudiante de derecho y humanidades, Palma debió entender el significado de la palabra nación. Como se sabe, en el siglo XIX la nación era concebida (de manera teórica por la elite criolla) como una comunidad que poseía en común los siguientes elementos: territorio, economía, población, religión, lengua, pasado y proyecto futuro; definición decimonónica, que empezó a difundirse con mayor amplitud por aquel momento, desplazando el antiguo concepto de que la nación es una lengua, una raza, de corte étnico y lingüístico.

Durante la infancia y adolescencia de Palma, las noticias políticas daban cuenta de que los caudillos militares en su pugna por el poder hacían un llamado a la Nación. El presidente de la República, los ministros y parlamentarios también hacían lo propio. El llamado a la nación era el llamado al pueblo, a todos los peruanos. Palma debió entenderlo así, por lo que logró familiarizarse rápidamente con esta palabra.

\section{El movimiento romántico y el surgimiento de una literatura nacional.}

En 1848, el movimiento del romanticismo se hace presente en el Perú gracias a la labor proselitista del poeta español Fernando Velarde. Muchos jóvenes y estudiantes sucumben a esta nueva moda literaria, entre ellos, Palma. El amor por la lectura y la devoción por los clásicos exponentes de esta corriente (Dumas, Lamartine, Espronceda, Zorrilla, Campoamor) hacen que muchos jóvenes se inclinen a la actividad literaria. Influenciado por esa moda literaria Palma realiza en ese año, sus primeras composiciones literarias. Su dominio de la pluma es innato. Ese talento lo llevará a incursionar, con tan solo quince años, en el mundo del periodismo. El medio de prensa que lo tendrá entre sus filas será El Diablo, un semanario limeño opositor al gobierno de Castilla. 
Como muchos de los románticos Palma se nutrirá de los ideales de esta corriente (el amor a la patria, el culto a los héroes, la importancia de la tradición, y el rescate del pasado) los cuales los pondrá de manifiesto en su obra.

Por efecto de esta corriente, los románticos producirán, en la década de 1850, una literatura patriota: José Arnaldo Márquez (La bandera de Ayacucho), Manuel Nicolás Corpancho ( $E l$ barquero y el Virrey), Luis Benjamín Cisneros (El pabellón peruano). Palma no se quedará atrás. Contagiado por un desbordante patriotismo compondrá en 1851 un lindo poema ("A mi patria. En el aniversario de la proclamación de su Independencia"), cuyos extractos presentamos a continuación:

$$
\begin{aligned}
& \text { Pueblo! La enseña de un rey } \\
& \text { Aquí flamear no se vea, } \\
& \text { La libertad tu Dios sea, } \\
& \text { Y su altar solo la ley. } \\
& \text { Y comprenderá el tirano } \\
& \text { Que esclavizarnos intente, } \\
& \text { Que el Perú es independiente } \\
& \text { Yel pueblo es soberano }
\end{aligned}
$$

Como se puede observar en esta octava, Palma tenía una idea aproximada de lo que era la nación, por ello su verso nacionalista. Concibe al Perú como un Estado independiente, mientras que el pueblo (aunque no lo menciona explícitamente) un elemento constitutivo de la nación, que logra ejercer su soberanúa. Esto debió de aprenderlo en las aulas de San Carlos (centro de las ideas conservadoras en donde se ensentaba la teoría de la Soberanía de la Inteligencia de su rector Bartolomé Herrera), ya que por entonces "hubo lujo de tolerancia con la juventud que defendía el principio de la soberanía popular"

1 Citado en Holguín Callo (1994: 227). 
(Palma, 1964: 1495).Tal vez como muchos hombres de su tiempo, Palma haya empleado de manera similar los conceptos de patria y nación. Lo cierto es que en el siglo XIX ambos términos tenían similar connotación. Incluso, "por influencia europea la Patria expresa y hasta se confunde con la nación" (Maticorena Estrada, 1993: 45).

La importancia que tiene la literatura es gravitante para los jóvenes románticos. Por un lado, algunos tratarán de copiar a autores extranjeros, mientras que otros, más nacionalistas, apostarán por incluir en sus producciones a personajes locales, héroes y lugares del territorio nacional.

En 1851, Palma escribió su obra de teatro Rodit, en donde representó la gesta del bravo general español Juan Ramón Rodil en el puerto del Callao en 1825. La obra exhibe ribetes de patriotismo de parte de los soldados peruanos, pero también resalta la valentía del militar español. Precisamente en esta obra, Palma se valdrá en una de sus escenas para atacar al gobierno del presidente Echenique (quien gobernaba por entonces) por la aprobación de la "Ley de represión". En ella hará alusión a la nación y lo hará del siguiente modo:

Aquí donde es ironía

Hasta la luz que fulgura

Nos postramos con pavrura

Delante de la tiranfa;

Y oprimido el corazón

Rompe el pintor su paleta,

$\mathrm{Y}$ aquí maldice el poeta

Su lira y su inspiración

Un porvenir no tenemos

No hay lauros para la sien,

Y el sarcasmo y el desdén

Solamente merecemos 
iDesgraciada la nación

Donde se humilla el talento,

Y hasta para el pensamiento

Hay leyes de represión!!!?

Como podemos notar, Palma hace mención a la nación. Compartía su gusto por la literatura, pero estaba también al tanto de la política nacional. Por entonces, era un estudiante pobre y como parte del pueblo mostraba su rechazo hacia una ley que atentaba las libertades individuales e impedía el derecho a la insurgencia.

\section{La importancia de la historia en las primeras obras de Palma.}

Durante la década de 1850 , la influencia del romanticismo no solo se hizo sentir en el campo de la literatura, sino que tuvo marcada incidencia en el campo de la historia. Hubo una gran revalorización del pasado y muchos intelectuales peruanos y extranjeros ayudaron en ello. Entre los más destacados figuran los nombres del español Sebastián Lorente (a quien Palma escuchó en las aulas del colegio Guadalupe dando lecciones de historia y literatura), autor de uno de los primeros textos escolares en el Perú, y el escritor chileno Manuel Bilbao, autor de la Historia del general Salaverry.

Como muchos de sus compañeros de generación, la llamada Bohemia Limeña, Palma entrelazó la literatura con la historia. En efecto, a partir de 1852, empezó a componer sus primeros relatos literarios de corte histórico, a los que bautizó con varios nombres; leyendas nacionales, romances históricos, romances nacionales, cuento nacional, tradición nacional, que fueron

2 Palma (1851: 17). 
sus primeros ensayos de sus tradiciones ("Flor de los cielos", "Mauro Cordato" y "Lida"). Sin embargo, su mejor interés por la historia por estos años se ve reflejado en su folleto Corona Patrítica (1853), una serie de relatos biográficos en donde su autor resalta la acción de los precursores de nuestra independencia. En este pequeño trabajo Palma expresa su fe en el porvenir, es decir, cree en un proyecto a futuro, elemento importante de la nación.

\section{La Revista de Lima. El nacionalismo criollo}

En 1859, Palma ejercía la labor periodística en al gunos periódicos de la capital. Había sido separado de la Marina por su apoyo a la rebelión del general Vivanco. Su vida transcurría entre las salas de prensa y las animosas reuniones con sus compañeros de la Bohemia Limeña. Había dejado atrás la pobreza y formaba parte de la clase media. Sin embargo, al ser un intelectual y rodearse con gente de la elite, aspiraba a convertirse en un miembro más de aquel grupo social.

Precisamente, formando parte de la intelectualidad limeña, colaboró por ese año en La Revista de Lima, órgano de la elite intelectual criolla. En esta importante revista, sus colaboradores (Pardo, Ulloa, Camacho, Lavalle, Márquez, Cisneros y el propio Palma) tenían una idea clara sobre la construcción de la nación peruana. El nacionalismo de esta intelectualidad criolla se encuentra reflejado en los numerosos artículos, en los cuales se puede apreciar el amor al territorio nacional, el deseo de contar con una literatura de tipo nacional, el rescate de nuestra memoria colectiva, el conocimiento científico de nuestra flora, fauna, y el desarrollo del país.

Todos los intelectuales de esta revista tuvieron una idea de nación o en todo caso una nación pensada desde la elite, que 
tenía como su punto de partida en el centralismo limeño, asociados a los intereses de la oligarquía comercial limeña, que anhelaba la supremacía de la capital sobre el territorio del país. Por ello, la mayoría de los integrantes de La Revista de Lima, "asumieron su radical desconfianza frente a los proyectos provenientes del lado oscuro de la sociedad: lo indio, lo mestizo y lo andino" (Del Castillo, 2000: 126).

Estrechamente vinculado a este grupo intelectual, Palma dejó de pensar en la nación como objeto de integración y unidad. Su mente ahora le decía que la nación debía construirse partiendo de los intereses de la élite.

\section{La vinculación con la élite. La política y el proyecto nacional de Balta}

Alcanzar una buena posición social y hacerse de un nombre era el sueño de Palma y de muchos intelectuales de las clases pobres y medias. Para conseguir tan ansiado objetivo la única forma de conseguirlo era vincularse con el mundo de la política. En efecto, muchos jóvenes intelectuales establecieron amistad con personajes cercanos al gobierno y a la oposición. La meta era apoyar a un determinado caudillo militar y, luego, ver la manera de obtener un nombramiento en el sector público. Gracias a la ayuda de un amigo, Palma logra acercarse al círculo de gobierno del presidente Pezet. Este lo nombró, en 1863, cónsul en el Brasil. Emprende el viaje y hace un alto en Europa. En el viejo continente (donde estuvo nueve meses), el flamante diplomático conoció Inglaterra, Francia, Italia y Bélgica, logrando distinguir el marcado nacionalismo de sus habitantes. Como peruano, el sentimiento nacional lo embargaba.

Alenterarse dela amenaza europea sobresus antiguas posesiones americanas se llenó de patriotismo, llegando a mostrar su 
rechazo ante estos afanes colonialistas. Posteriormente, emprende su viaje a Brasil. Llega a la zona del Pará pero es impedido de hacerse del cargo consular por órdenes superiores. Desalentado, en 1865, realiza el viaje de retorno. Se dirige a los Estados Unidos, Panamá, Ecuador, e ingresa al Perú por el puerto de Paita. Una vez en el país, se enrola en las huestes revolucionarias del coronel José Balta, convirtiéndose en su secretario. Al ser depuesto Pezet, el gobierno de Prado lo nombra funcionario de la Secretaría de Guerra y Marina, teniendo como jefe a su antiguo líder José Gálvez. Ante la presencia de la flota espanola, Prado hace un llamado a la nación, acudiendo muchos peruanos, entre los cuales se encontraba Palma. Tal vez, en ese momento, pudo pensar (como más adelante lo pensara Ernest Renán) que la nación se expresaba en la solidaridad de sus habitantes, lo cierto es que se entregó con valentía, para luego celebrar de aquella victoria. Partícipe de este triunfo, Palma escribiría dos años después un poema, en donde alabó a la nación:
Gloria al Perú que ha sabido
Rechazar la humillación
Y tenga para el recuerdo
De ignominia el español.
La aurora del Dos de Mayo
Que hizo grande a esta Nación ${ }^{9}$.

Tras el triunfo peruano y la muerte de Gálvez, Palma se vuelve opositor al gobierno de Prado y se une a la causa del coronel José Baltä, convirtiéndose en su secretario personal. Al triunfar la revolución, el héroe de Chiclayo es elegido presidente de la República y el tradicionista, como hombre de su confianza, el encargado del despacho presidencial.

3 El Comercio. Lima, 4 de mayo de 1868. "Crónica Interior", p. 3. 
Por primera vez en su vida, Palma se encaramaba en la cima del poder. Hombre de armas, Balta distaba mucho de ser un estadista, pero como todo caudillo sabía utilizar sus redes de dientelaje para ejecutar su proyecto político en provecho de la nación. En ese sentido, intentó reconstruir el antiguo esquema de apaciguamiento nacional diseñado por Castilla. Para comprar la tregua el caudillo norteño implementó una política de alianzas y acuerdos, e incluso organizó, en el más puro estilo castillista, un gabinete de conciliación nacional, conformado por diversas personalidades de la política y del ejército, y de distinta filiación ideológica (Mc Evoy, 1997: 40). Muchos personajes colaboraron con él, tanto civiles como militares. Entre ellos, el mismo Palma, quien acudía, en su condición de secretario, a las sesiones del Consejo de Ministros.

El proyecto político de Balta era de tipo conservador. Agrupaba a caudillos militares, terratenientes regionales, intelectuales y un sector laico. Según señala Riva Agüero, Palma "fue quien por primera vez puso en contacto al joven escritor D. Nicolás de Piérola con Balta", quien llegó a designarlo después como su ministro de Hacienda (Riva Agüero, 1920: 16-17). Balta aspiraba la construcción de la nación a través del Estado. En su. afán integrador impulsó una campaña de obras públicas y la construcción de rutas ferroviarias que conectarían ciudades y pueblos, elementos esenciales para el desarrollo de la nación. Ello se llevó a cabo tras la firma del Contrato Dreyfus. Palma saludó la propuesta del Jefe de Estado. Había visto en Europa el triunfo de la locomotora como base del desarrollo de las naciones. Como parte del proyecto modernizador, Palma (elegido en 1868 senador por Loreto) defendió desde el Parlamento las propuestas del Ejecutivo. Pero en algunos casos discrepó. Así, pues, al suspenderse los efectos del Decreto Supremo por el que se ordenó que en el monumento del 2 de Mayo, que se construía en Europa, se suprimiesen las figuras alegóricas y ordenase que 
se debería considerar siempre en el monumento el busto del doctor don José Gálvez. Palma presentó una propuesta a fin de continuar con la realización de la obra. A pesar de que su proyecto no encontró buena acogida en muchos representantes, el tradicionista dejó en claro su punto de vista:

Los fundamentos del decreto que combate mi proposición, insisto, se limitan a establecer que en ningún monumento nacional se colocan alegorias individuales, sino las alegorías mitológicas o paganas. No sé de donde pudo sacar el gobierno este argumento. Hay un monumento que vosotros conocéis, la columna de Vendome, que sin embargo de ser una colımna nacional, que representa las glorias del Imperio en los veinte años de triunfo que alcanzo la Francia, en su cúspide lleva la figura de Napoleón el Grande; es un monumento nacional y, no obstante, tiene alegoría personal, como muchos otros monumentos históricos. Pero aún hay más, señor. Tengo en la mano la tarjeta del monumento que se está construyendo en París. La figura del coronel Gálvez está al pie del monumento y domina el obelisco una llama que representa la Victoria"4.

Como se puede apreciar, Palma estaba a favor de la construcción del monumento. Gálvez debía de ser elevado a la categoría de héroe nacional, y suvaliente gesto debía ser evocado, unificando de esta manera a los integrantes de la nación. Como bien dice Thomas Benjamín:

Los monumentos conmemorativos tienen como objetivo más evidente la evacación y celebración del pasado en el presente. Son construidos a la memoria de héroes o acontecimientos por varias razones, aunque no siempre resulten muy claras (....) Como símbolos de la gloria

4 Sesión preparatoria del 27 de julio de 1968. Citado en Miro (1953: 93). 
y triunfos nacionales, los monumentos promueven la solidaridad horizontal y vertical; es decir, hacen que personas de distintas localidades, clases y etnias, lo mismo que de distintas generaciones, se consideren a si mismas como un pueblo, una nación (Benjamín, 1996:113-114).

Esta afirmación deja al nombre de Palma, como uno de los pilares en la construcción de la nación peruana.

Por otro lado, como representante por Loreto, apoyó el desarrollo de este departamento, exigiendo con justo derecho un mayor apoyo presupuestario para este. La siguiente cita da cuenta de esa preocupación:

El Departamento que represento, así como el Departamento de Amazonas, parece que fueran los pueblos desheredados de la República. Mensualmente se mandan contingentes a Loreto; pero esos contingentes no llegan precisamente a la capital del Departamento, sino al pueblo de Iquitos que es donde está establecida la factoría; y a los veinte días que llegan esos contingentes, no se encuentra un solo sol, porque todos marchan al Brasil[...] porque la moneda circulante es la feble boliviana, por cuya causa sufre notablemente el comercio 5 .

En sus cuatro años como secretario de la Presidencia, Palma compartió con el Jefe de Estado su preocupación por el Perú. Como secretario, Palma se ocupó de programar la agenda del Presidente. Asimismo, se encargó de otras labores, tales como atender a las distintas personalidades civiles y militares que deseaban entrevistarse con el mandatario, escribir diversos oficios de carácter gubernamental y proyectos del Ejecutivo,

5. Sesión del 13 de enero de 1869 , p. 662. Citado en Pérez Garay (2012: 171-172). 
redactar discursos para las distintas ceremonias oficiales del presidente, entre otros.

Precisamente, al inaugurar su gestión en 1868, Palma se encargó de escribir el mensaje a la nación del presidente Balta. En sus primeras palabras, señaló que su investidura al poder se debió al voto de la nación (Pérez Garay, 2015: 195), lo cual deja entrever que concebía a la nación peruana como sinónimo de pueblo.

Tras el asesinato de Balta en 1872 por obra de los hermanos Gutiérrez, Palma se dedica casi por completo a la literatura. No obstante, el nuevo gobierno de Manuel Pardo lo sindicó como uno de los defensores de la pasada administración, por lo que será víctima de una campaña de desprestigio político por parte de un sector del civilismo, que estaba asociado al grupo de la burguesía comercial limeña, que fueron perjudicados por la firma del Contrato Dreyfus de 1870 . Precisamente, el ascenso al poder de Pardo "se debió a la fuerza de este grupo social limeño. Pero este grupo se interesaba más por sus negocios que por el desarrollo del país" (Mucke, 2010: 305).

\section{Las Tradiciones Peruanas como base para la construcción de un imaginario nacional}

En 1872, Palma publicó en Lima su primera serie de tradiciones. En esos cortos relatos de base histórica y algo de ficción, a los que se suman una carga de ironía, sarcasmo y humor, Palma dejó en claro su amor por el Perú, identificándose con su pasado, su presente y su futuro. En lo que se respecta, al primer punto, el hecho de que Palma tome como fundamento de sus tradiciones el pasado de su país se justifica en esa necesidad de construir un imaginario de carácter histórico que se plantea la posibilidad de relatar un pasado y compartir un futuro mejor, es 
decir, de construir la identidad de su país e incluso su identidad personal, con lo cual queda definida su idea de nacionalidad.

Palma a través de sus Tradiciones Peruanas, intenta formar la idea de nación en sus contemporáneos. Todos la buscaban en aquella época: podríamos decir que el Perú se había independizado antes de existir como nación, y todos deseaban edificarla, cada uno a su manera: unos creando un estado, otros creando una literatura.

En este aspecto (la construcción del imaginario nacional en las tradiciones), es importante destacar el libro de Benedict Anderson Comunidades Imaginadas, en donde se plantea que los imaginarios nacionales son productos culturales de esencia colectiva que deben ser entendidos y estudiados desde una perspectiva histórica. En esa línea reflexiva, Anderson cree que la imprenta y el papel generaron un poderoso universo de lectores sobre el cual se construiría la opinión pública. Precisamente, para el historiador norteamericano, esos lectores formaron "en su invisibilidad secular, particular, el embrión de la comunidad nacionalmente imaginada" (Anderson, 1993: 73).

Otro trabajo importante es el de Gustavo Faverón: "Escribir la ficción, escribir la nación: el espejo roto de Ricardo Palma", en donde hace un análisis de la principal obra del escritor limeño a partir de los enfoques teóricos de Anderson, Eric Hobsbawm ( $\mathrm{La}$ invención de la tradición), Fredericjameson (Alegoría de la nación) y el trabajo de Doris Sommer: Ficciones Fundacionales, quien —en base a las ideas del historiador norteamericano- plantea que las novelas suponen y fundan las naciones modernas. Segun Sommers, en los romances históricos de mitad del siglo XIX, se articularía a través de la ficción, la unidad necesaria para el proyecto nacional. Precisamente, Faverón cuestiona la teoría de Sommer debido a que el concepto de alegoría que maneja presupone un impulso unificador y que no da cuenta en su trabajo de las fisuras existentes (Faverón, 2005: 104). 
El sociólogo Gonzalo Portocarrero tiene también un agudo análisis sobre la principal obra de Palma. Siguiendo la influencia de la teoría postcolonial Portocarrero plantea que detrás de las tradiciones se esconde un proyecto político. En este proyecto, existe la necesidad de crear un sujeto colectivo que diera estabilidad a la realidad política del Perú de mediados del sigo XIX, pero que no alterase las jerarquías ni las profundas divisiones sociales (Portocarrero, 2007).

A diferencia de otros autores que se ciñen a una teoría, el historiador Joseph Dager presenta un buen análisis de la principal obra de Palma. Según Dager "con sus tradiciones, Palma buscó ofrecer pequeñas estampas que otorgasen a sus lectores referentes concretos con los cuales identificarse. Para eso apeló al pasado. (......) La comunidad que imaginó Palma, y que se difundió extensamente, fue una comunidad básicamente criolla, es decir, fundamentalmente occidental y urbana. No excluyó el elemento andino representado por los incas a quienes dedicó algunas tradiciones, pero los grupos subalternos de los que fue contemporáneo apenas si fueron mencionados, estuvieron casi silenciados como afirmarian los estudios poscoloniales" (Dager, 2009: 152).

A pesar de todas las críticas, Palma será un personaje polémico que seguirá dando que hablar. Lo importante es que en su obra se puede notar todos los elementos de la nación. En efecto, presenta al territorio. Señala las ciudades importantes del Perú: Lima, Cusco, Huamanga, Trujillo, Arequipa, Piura, Chiclayo. Ciudades menores: Huaura, Pisco, Huacho, Junín, Ayacucho Paita, Huamachuco, Locumba, Yauli, Corongo, Concepción, Tarapacá, Arica, Huaraz, etc. Está también el pueblo, en donde se puede apreciar los grupos sociales, estamentos, razas, castas. Asimismo está la lengua española, elemento integrador de la sociedad peruana. En muchas de las tradiciones Palma apela a los neologismos, enriqueciendo el idioma español con 
sus peruanismos y americanismos. También está la religión, institución que aglutina a todos los peruanos. Igualmente, la economía, al presentar a sus personajes en sus diversas actividades económicas: artesanos, mercaderes, aguadores, mercachifles, buhoneros, etc. Importancia del mercado y las ferias.

\section{Palma y su idea de nación durante la guerra con Chile}

Durante la guerra con Chile la idea de nación de Palma sufrirá ligeras modificaciones. Uno de los puntos más discutibles es su posición con respecto a la raza indígena. En su carta del 13 de enero de 1881 al presidente Piérola se la manifestó del siguiente modo:

En mi concepto, la causa principal del gran desastre del 13 está en que la mayoría del Perú la forma una raza abyecta y degradada, que usted quiso dignificar y ennoblecer. El indio no tiene el sentimiento de patria; es enemigo nato del blanco y del hombre de la costa $y$, señor por señor, tanto le da ser chileno como turco. Así me explico que batallones hubieran arrojado sus armas en San Juan, sin quemar una cápsula. Educar al indio, inspirarle patriotismo será obra no de las instituciones sino de los tiempos. Por otra parte, los antecedentes históricos nos dicen con sobrada eloctencia que el indio es orgánicamente cobarde. Bastaron 172 aventureros españoles para aprisionar a Atahualpa, que iba escoltado por cincuenta mil hombres, y realizar la conquista de un imperio, cuyos habitantes se contaban por millones. Aunque nos duela hay que convenir en que la raza araucana fue más viril, pues resistió con tenacidad a la conquista (Palma, 1964: 20).

Como se puede apreciar, la posición de Palma frente al indio es claramente racista y discriminatoria. De hecho, en la derrota 
siempre se busca culpables directos, y Palma así lo hizo. Señaló al indio. Pero todo esto tiene una explicación. Por el último cuarto del siglo XIX, muchos intelectuales latinoamericanos, incluyendo Palma, se sintieron atraídos por las ideas positivistas (orden y progreso), la corriente naturalista y el darwinismo social. Se hablaba de la superioridad de la raza y la idea de homogeneidad. Constituir una nación homogénea, emparentadas a través de la historia, la lengua y la raza fue el deseo de muchos intelectuales. Uno de ellos fue, incluso, un amigo de Palma, el argentino, Vicente Fidel López, quien señalaba, en base a sus estudios, que la nación andina, los llamados "incas arios", eran el elemento seminal de la nacionalidad (Quijada, 1996: 249).

Si en un momento Palma creyó que la nación podía ser una suma de voluntades, lazos de solidaridad y un sentimiento, como mas tarde lo expresaría Ernest Renan (2002: 11), la derrota lo hizo cambiar inmediatamente de opinión. Tal vez, como dice Osmar Gonzales, "los prejuicios de Palma hacia el contingente indígena podrían ser explicados por los seculares resentimientos que marcaron las relaciones entre los diferentes grupos étnicos -y que aún permanecen-" (Gonzáles, 2001: 88 ). Por estas controvertidas expresiones, el tradicionista:

Obnubiló su visión con respecto a sus compatriotas, alejándose de sus convicciones democráticas e igualitarias enseñadas por su maestro José Gálvez. No obstante, con el paso del tiempo, las apreciaciones del tradicionista sobre el tema indígena se irán reformulando, gracias a la lectura de libros referidos al tema, y sobre todo a la influencia decisiva del realismo, la corriente literaria del siglo XIX, que tenía como rasgo principal, el cuestionamiento y la crítica - mediante el ensayo y la novela - de los principales problemas que aquejaban a la sociedad. Precisamente, una muestra del cambio de Palma en el tema indigena, se puede observar a través de su ensayo titulado "Justicia y Escuelas", 
en donde plantea la urgente necesidad de una educación inclusiva para todos los peruanos, sin distinción de razas. (Pérez Garay, 2015: 268-269).

Ahora bien, lo único que podemos afirmar, de acuerdo a lo mostrado, es que por entonces, el tradicionista logró tener una imagen pesimista de la nación peruana.

\section{Palma y su aporte a la cultura nacional}

Considerado como uno de los máximos exponentes de la literatura nacional, Palma contribuyó a forjar nuestra cultura nacional. Ello se puede ver a través de su labor en diversas instituciones. Fue director de la Biblioteca Nacional luego de la guerra con Chile, y fue el encargado de las labores de reconstrucción. Asimismo, fue Presidente de la Academia Peruana de la Lengua, la Sociedad Geográfica de Lima, Sociedad Vencedores de la Independencia, entre otras más. Entre sus distintos aportes, figura el enriquecimiento del idioma español con palabras de origen peruano (peruanismos), siendo junto a Juan de Arona uno de los mejores exponentes de la lengua en el Perú.

\section{Conclusiones}

En el presente trabajo podemos señalar algunas conclusiones sobre la idea de nación que tiene el ilustre tradicionista Ricardo Palma.

1. Palma no tuvo una idea clara y permanente del concepto de nación. Por momentos asocia a la nación con la raza, luego con el sentimiento y posteriormente con un conjunto de voluntades. 
2. En lo que se refiere a la literatura, Palma contribuye considerablemente a la creación de una literatura nacional. En su obra, logra presentarnos diversos escenarios y paisajes del Perú, lo mismo que una gama de personajes vinculados a este territorio y muestra, de manera clara, el carácter e idiosincrasia de sus habitantes. En ese sentido, las tradiciones vienen a ser la expresión de nuestra identidad peruana.

3. Para el tradicionista, el Estado debe jugar un papel importante en la construcción de la nación. Para tal objetivo, la educación se convierte en un pilar fundamental. La tradición "Justicia y escuelas" expresa mucho de ello.

4. Como muchos intelectuales peruanos, Palma creyó en los proyectos políticos nacionales. Cree que un gobernante encarna los designios de la nación. Por tanto, el objetivo de estos es buscar la felicidad social.

5. Un elemento constitutivo de la nación, de suma importancia para Palma, es el pasado. En muchas de sus obras, hay un intento de revalorar la historia y rescatar la memoria colectiva de todos los peruanos.

6. A pesar de sus diversas propuestas ideológicas, incluso hasta las más polémicas, Palma fue uno de los forjadores de la nacionalidad peruana. Su aporte a la literatura, la lengua, la historia y la cultura es ampliamente valorada por muchas generaciones de peruanos.

7. Si de nacionalismo se trata, podemos afirmar que Palma alcanzó, en un momento de su vida, a mostrar simpatía por el nacionalismo criollo, aquel nacionalismo dela élite intelectual criolla del siglo XIX, cuyos máximos portavoces son los miembros de La Revista de Lima. Estos se caracterizaron por tener una visión poco integradora de la sociedad peruana, 
ya que muchos de ellos, por estar vinculados a la oligarquía comercial limeña, no podían imaginar que los indios, negros y otras castas, pudieran formar parte de la nación, por su analfabetismo, costumbres, lengua, etc. No obstante, con el transcurrir de los años, su nacionalismo se irá perfilando, logrando comprender a todos los peruanos.

\section{Bibliografía}

ANDERSON, Benedict. Comunidades imaginades. Reflexiones sobre el origen y la difusión del nacionalismo. México D.F: Fondo de Cultura Económica, 1993.

BENJAMÍN, Thomas. "La Revolución hecha monumento", en Historia y Grafia (1996), pp. 113-139.

DAGER ALVA, Joseph. Historiografia y Nación. Lima: PUCP, 2009.

DEL CASTILLO, Daniel "Un deseo de historia. Notas sobre intelectuales y nacionalismo criollo en el siglo XIX a partir de La Revista de Lima (1859. 1863)", en Henriquez, Narda (compiladora). El hechizo de Las imágenes. Estatus social, género y etnicidad en la historia peruana. Lima: PUCP, 2000, pp. 99-195.

FAVERÓN PATRIAU, Gustavo. "Escribir la ficción, escribir la nación: el espejo roto de Ricardo Palma", en Quehacer (Lima, 2005) 157 , pp. $100-107$.

GONZALES. Osmar. "Ricardo Palma y Manuel Gonzales Prada. Conflicto entre dos tipos de intelectuales", en Fénix (Lima, 2001-2002) 43-44, pp. $79-97$.

HOLGUIN CALLO, Oswaldo. Tiempos de Infancia y Bohemia. Ricardo Paima (1833-1860).

MATICORENA ESTRADA, Miguel. La idea de nación en el Perú. Lima: Ediciones Sequilao, 1993. 
MIRÓ, César. Don Ricardo Palma. El patriana de las tradiciones. Buenos Aires: Editorial Lozada, 1953.

Mc EVOY, Carmen. La utopia republicana. Ideales y Realidades en la Formación de la Cultura Política Peruana. Lima: PUCP, 1997.

MUCKE, Ulrich. Política y burguesía en el Perú. El Pattido Civil antes de la Guerra con Chile. Lima: IFEA-IEP, 2010.

PALMA, Ricardo. Tradiciones Peruanas Completas. Madrid: Aguilar, 1964.

— Cartas inéditas. Introducción y notas de Rabén Vargas Ugarte. Milla Batres: 1964

PÉREZ GARAY, Carlos. Liberalismo criollo. Ricando Palma. Ideologia y politica (1833-1919). Lima: Editorial Universitaria. URP, 2015.

QUIJADA, Mónica. "Los incas arios. Historia, lengua y raza en la construcción nacional hispanoamericana del siglo XIX, en Histórica (Lima, 1996) vol. XX, 2, pp. 243-269.

RENAN, Ernest. "¿Qué es una nación?" (Conferencia dictada en la Sorbona, el 11 de mayo de 1882). Lima: IEP, 2002 (Taller interactivo: Prácticas y Representaciones de la Nación, Estado y Ciudadanía en el Perí). 